\title{
EL RETORNO A LA OBEDIENCIA DE JUAN I: LA REINSTAURACIÓN DE LAS DÉCIMAS PONTIFICIAS $(1387-1393)$
}

\author{
Esther Tello HernándeZ \\ Universitat de València
}

Recibido: 30 de abril de 2020

Aceptado: 12 de mayo de 2020

\begin{abstract}
Resumen
En 1387, el papa aviñonense Clemente VII promulgó tres décimas pontificias en la Corona de Aragón que debían servir para sufragar los gastos que ocasionaban las revueltas en Cerdeña. Parte de la colecta se destinó al rey aragonés Juan I que acababa de acceder al trono tras la muerte de su padre. Se desmarcaba así de su predecesor, quien se había incautado durante nueve años de las rentas de la Cámara Apostólica. En este artículo se estudia el retorno a la obediencia de Juan I y la reinstauración progresiva del aparato fiscal y financiero pontificio en la Corona de Aragón a través de la recaudación y gestión del tributo de la décima papal.
\end{abstract}

\section{Palabras clave}

Corona de Aragón, siglo XIV, fiscalidad pontificia, finanzas públicas, décima

\begin{abstract}
Pope Clement VII of Avignon promulgated in 1387 three papal tithes in the Crown of Aragon in order to support the expenses caused by the riots in Sardinia. Part of the takings were destined to the Aragonese King John I, who had just acceded to the throne. With this action, King John I dissociated himself from the previous king - his father, who had appropriated the income of the Apostolic Chamber for nine years. This article studies the return of John I to the obedience, the progressive reestablishment of the pontifical fiscal system and the financial structure in the Crown of Aragon through the collection and management of the tribute taken by the papal tithes.
\end{abstract}

\section{Keywords}

Crown of Aragon, 14th century, pontifical taxation, public finance, papal tithes.

\section{Riassunto}

Nel 1387, il papa Clemente VII di Avignone promulgò tre decime papali nella Corona d'Aragona che serviranno a coprire le spese causate dalle rivolte in Sardegna. Una parte della raccolta fu destinata

Contratada postdoctoral Juan de la Cierva. Departamento de Historia Medieval. Universitat de València Facultad de Geografía e Historia. Av. de Blasco Ibáñez, 28, 46010, Valencia. Correo electrónico: esther.tello@uv.es. OrCID: https://orcid.org/0000-0002-5985-3791. 
al re aragonese Giovanni I, appena salito al trono dopo la morte del padre. Si staccò così dal suo predecessore, che per nove anni si era appropriato delle entrate della Camera Apostolica. Questo articolo studia il ritorno all'obbedienza di Giovanni I e la progressiva restaurazione dell'apparato fiscale e finanziario pontificio nella Corona d'Aragona attraverso la raccolta e la gestione del tributo della decima papale

\section{Parole chiave}

Corona d'Aragona, XIV secolo, tasse pontificie, finanze pubbliche, decima

\section{Introducción: el retorno a la obediencia aviñonesa}

Una de las primeras acciones que llevó a cabo Juan I de Aragón (1387-1396) cuando comenzó su reinado fue declarar la obediencia al papa de Aviñón Clemente VII (13781394 $)^{2}$. Rompía así con la tradición iniciada por su padre nueve años atrás, cuando, al comienzo del Cisma de Occidente, Pedro IV (1336-1387) se proclamó indiferente o neutral ante el papado y retiró su fidelidad tanto al papa aviñonés, Clemente VII, como al romano, Urbano $\mathrm{VI}^{3}$. Este hecho de gran transcendencia supuso, nada más y nada menos, que durante nueve años el rey se apropió de las rentas ordinarias de la Cámara Apostólica que se recaudaban en los territorios que formaban la colectoría de Aragón (anatas, vacantes, restas de décimas, etc.). Para ello, desde la monarquía se creó un aparato administrativo propio que gestionaba los ingresos y gastos de estas exacciones; es lo que historiográficamente se conoce como la Cámara Apostólica Real ${ }^{4}$. Pues bien, cuando Juan I restituyó la obediencia a Clemente VII, la Cámara Apostólica Real quedó desmantelada y se puso de nuevo en marcha el funcionamiento ordinario de la Cámara Apostólica de Aviñón. Dicho de otro modo, una serie de colectores y subcolectores apostólicos volvieron a percibir los tributos pontificios arriba men-

\footnotetext{
Este trabajo forma parte de los grupos de investigación Desigualdad económica y movilidad social en la Europa Mediterránea, siglos XIII-XVI (ref. Prometeo2019/072) y Renda feudal i fiscalidad a la Catalunya Baix-Medieval (ref. 2017-SGR-1068), y se ha desarrollado en el marco de los proyectos de investigación del Ministerio de Ciencia, Innovación y Universidades ¿Crecimiento sin desarrollo? Distribución de la riqueza, movilidad social y acción política en la Europa Mediterránea (siglos XIII-XV) (ref. PGC2018099275) de la Universitat de València y La desigualdad económica en las ciudades catalanas y mallorquinas durante la baja Edad Media (ref. PGC2018-100979-B-C22) de la Institución Milá y Fontanals (IMF-CSIC. Barcelona). Abreviaturas utilizadas: ACA = Archivo de la Corona de Aragón; RP = Real Patrimonio; MR = Maestre Racional; $\mathrm{C}=$ Real Cancillería; reg. = registro; vol.= volumen. Las cantidades monetarias se expresan en libras, sueldos y dineros barceloneses (1.b., s.b., d.b.) y florines de Aragón (fl.). Este artículo se terminó de redactar en la extraña primavera de 2020. Desde aquí, un reconocimiento a todos aquellos que han cuidado y cuidan de nosotros.

3 Como referencia general al periodo de la indiferencia del Ceremonioso, véanse: Ivars, La indiferencia de Pedro IV de Aragón; TAsis i MARCA, "La indiferencia de Pere III", pp. 107-111.

4 Este término fue acuñado por los hispanistas alemanes en el siglo XX: VINCKE, "Eine königliche camera apostolica", pp. 306-310. Además, para comprender cómo se produjo la incautación de rentas pontificias por parte de Pedro IV y los mecanismos administrativos empleados, remito a VINCKE, "Estado e Iglesia", p. 277; Tello Hernández, “La Cámara Apostólica Real en la Corona de Aragón”, pp. 211-213.
} 
cionados en los territorios de la Corona. Entre todos ellos, nos ocupamos aquí de la décima pontificia, un impuesto que no se recaudaba desde 1378.

Como es sabido, la décima era un impuesto extraordinario que promulgaba el papa y que surgió a finales del siglo XII con el propósito de financiar las cruzadas a Tierra Santa o, más en general, de defender los intereses de la Santa Sede. Para ello, se gravaban los beneficios eclesiásticos con un porcentaje variable -en este caso el 10\%- de la renta anual neta a lo largo de un año ${ }^{5}$. En el del siglo XIV, los monarcas del occidente cristiano se beneficiaron en buena medida de este impuesto, con una finalidad que distaba de su función originaria. En la Corona de Aragón, durante la segunda mitad del siglo XIV (a excepción de los años en los que el Ceremonioso se declaró neutral), la décima se promulgó una y otra vez para hacer frente, teóricamente, a las revueltas de Cerdeña, territorio vasallo de la Santa Sede y del rey de Aragón, por lo que fue un asunto de primer orden para ambas potencias. Fruto de esta coyuntura, se convirtió en una exacción habitual que, auspiciada por el papado, acabó en manos -total o parcialmente- de los monarcas de la Corona de Aragón ${ }^{6}$.

Por ello, en las siguientes páginas nos centramos en la concesión de una serie de décimas pontificias que se promulgaron conjuntamente en 1387, justo cuando Juan I prestó su obediencia al papa aviñonés. En particular, hacemos mención tanto al modo de percepción, como a la forma en la que se gestionaron esos ingresos con el fin de mostrar cómo se insertaba la recaudación de un impuesto pontificio en el entramado fiscal y financiero de la corona, en un momento donde la mayor parte del numerario se destinaba al pago de los principales acreedores de la monarquía?

\footnotetext{
Para una definición del impuesto de la décima, en general, véanse como estudios de referencia: LunT, Papal Revenues, pp. 71-77; Mollat y Samaran, La Fiscalité pontificale, pp. 11-68.

6 Como veremos, durante buena parte del siglo XIV y hasta comienzos del siglo XV, la décima se convirtió en un recurso habitual para las arcas del rey. Para profundizar en el papel que jugó la décima en la fiscalidad regia de la Corona de Aragón durante este periodo, véanse, entre otros: BERTRAN Roigé, "La fiscalitat eclesiástica en els bisbats catalans", pp. 281-300; IDEM, "La Fiscalitat eclesiástica en els bisbat", pp. 291-293; SÁnchez Martínez, "Fiscalidad pontificia y finanzas reales en Cataluña", pp. 1277-1296; Morelló Baget, "En torno a la disyuntiva décima/subsidio", 643-671; Tello Hernández, Pro defensione regni, pp. 217-252.

7 Este estudio viene a completar así una serie de artículos y monografías publicadas desde finales del siglo XX que se han centrado en la recaudación del impuesto de la décima en la Corona de Aragón durante el siglo XIV. En particular, más allá de las obras citadas, las décimas de mediados de siglo fueron estudiadas, en parte, por M. Sánchez (SÁnchez Martínez, "Fiscalidad pontificia y finanzas reales en Cataluña"); para el resto del siglo XIV, las décimas seriadas han sido analizadas por E. Tello (TeLLo Hernández, Pro defensione regni); y para las décimas de fin de siglo, el estudio de referencia es el de J. Morelló (Morelló BAGET, "La contribución de la Iglesia a las arcas del rey: a propósito de la recaudación"). Como síntesis general para todo el periodo, véanse: Morelló BAGET, "En torno a la disyuntiva décima/ subsidio", pp. 643-671; Tello HernándeZ, "La comptabilité des décimes pontificales" (http://journals. openedition.org/comptabilites/2491).
} 


\section{La concesión de las décimas de $\mathbf{1 3 8 7}$}

Como decíamos, en 1387 el papa aviñonés Gregorio VII promulgó tres décimas pontificias de carácter bienal que se recaudaron, sin solución de continuidad, desde noviembre de 1387 hasta junio de $1393^{8}$. Las tres bulas de concesión se redactaron en Aviñón entre el 11 y el 15 de mayo de 1387 y la información que nos dan es muy similar. Cada una de las décimas estuvo vigente durante dos años y se recaudaron a lo largo y ancho de los obispados dos veces al año: en la festividad de Todos los Santos y en San Juan de junio. En los tres casos, además, el monto total se repartió entre el rey (quien percibió dos tercios del total de los ingresos) y el papa (al que fue a parar la parte restante) ${ }^{9}$.

\section{Cuadro 1.}

Concesión de las décimas pontificias (1387-1393)

\begin{tabular}{lllll}
\hline Décima & Bula de concesión & Colectores de las décimas & Pagas & $\begin{array}{l}\text { Nombramiento } \\
\text { de los } \\
\text { subcolectores }\end{array}$ \\
\hline Bienal 1387 & $11 / 05 / 1387$ & García Fernández de Heredia, & $01 / 11 / 1387$ & $28 / 06 / 1387$ \\
& & arzobispo de Zaragoza & $24 / 06 / 1388$ & \\
& & $01 / 11 / 1388$ & \\
& & & $24 / 06 / 1389$ & \\
\hline Bienal 1389 & $14 / 05 / 1387$ & Idem & $01 / 11 / 1389$ & $31 / 08 / 1387$ \\
& & & $24 / 06 / 1390$ & \\
& & & $01 / 11 / 1390$ & \\
& & $24 / 06 / 1392$ & \\
\hline Bienal 1391 & $15 / 07 / 1387$ & Idem & $01 / 11 / 1391$ & $24 / 10 / 1390$ \\
& & & $24 / 06 / 1392$ & \\
& & & $01 / 11 / 1392$ & \\
& & $24 / 06 / 1393$ & \\
\hline
\end{tabular}

Para llevar a cabo la recaudación del impuesto, se puso en marcha un complejo sistema de colectores, subcolectores y agentes laicos que se encargaron de percibir los ingresos y gestionar los gastos en cada uno de los obispados. Por lo que aquí nos interesa, el hecho de que dos tercios del total de cada diócesis fuera a parar a las arcas regias explica la gran cantidad de fuentes documentales conservadas en el Archivo de la Corona de Aragón. Y es que, recordemos que al igual que ocurría con otros tributos regios, los subcolectores eclesiásticos encargados de la recaudación de la décima debían presentar

\footnotetext{
8 En 1393 se promulgó otra décima y, a partir de entonces, la recaudación del impuesto se sucedió sin solución de continuidad hasta 1409 (Morelló BAGEt, "La contribución de la Iglesia a las arcas del rey: a propósito de la recaudación", pp. 174-178).

9 Así se establecía en las bulas de concesión y se copiaba tanto en las cartas de nombramiento de subcolectores como en los albaranes testimoniales que describimos a continuación.
} 
los libros de cuentas ante el maestre racional -principal oficial fiscal y financiero de la hacienda regia- cuando terminaba el proceso recaudatorio. Gracias a ello, se han conservado un elevado número de libros de cuentas, generalmente en buen estado, que recogen los ingresos de cada beneficio eclesiástico y los pagos de la colecta. Con la presentación de estos libros ante el maestre racional, se daba por finalizado el proceso recaudatorio y el racional expedía un albarán testimonial resultado de la audición final de las cuentas que clausuraba el proceso fiscalizador, hecho que-generalmente-ocurría tiempo después de finalizar la recaudación ordinaria. Por ello, en algunos casos, pese a que no disponemos del libro de cuentas, sí que hemos podido localizar el albarán testimonial donde se nos indican los datos más generales del proceso ${ }^{10}$.

\subsection{Los colectores y subcolectores en la Corona de Aragón}

Con la promulgación de cada décima se establecía un aparato administrativo ad hoc cuya finalidad era la gestión del impuesto ${ }^{11}$. Como era habitual, a la cabeza del mismo se situó un colector principal nombrado por el papa. Generalmente este cargo siempre recaía en obispos o arzobispos de las principales diócesis de la Corona. En los casos aquí estudiados, el colector designado por el pontífice fue García Fernández de Heredia, que por entonces ocupaba la silla arzobispal de Zaragoza. Este conocido noble y religioso aragonés, comenzó su carrera eclesiástica como canónigo de Mallorca y diácono de Sant Feliu de Gerona. En la década de 1370 ocupó la mitra de Vic y, de manera oficial, en 1387 fue proclamado arzobispo de Zaragoza ${ }^{12}$. Los colectores principales eran destacados personajes al frente de asuntos políticos y eclesiásticos que llegaron a alcanzar cierta transcendencia sobre todo en materia fiscal y financiera. Y, si bien generalmente eran obispos, la labor de colectores de décimas pocas veces aparece reflejada en otro tipo de documentación y no suele aparecer ni en los episcopologios de los mitrados ${ }^{13}$.

\footnotetext{
10 Este sistema de recaudación y audición ha sido descrito en las obras ya mencionadas. Véase como síntesis: Tello Hernández, "La comptabilité des décimes pontificales" (http://journals.openedition.org/ comptabilites/2491).

11 Del mismo modo, el aparato administrativo que se ponía en marcha cuando se proclamaba un impuesto pontificio, en general, o la décima, en particular, ha sido estudiado desde diferentes puntos de vista. Para la Corona de Aragón, remito al estudio de Morelló Baget, "La maquinaria fiscal del papado", pp. 65125. Para el caso castellano, francés, portugués e inglés, resulta también muy sugerentes los estudios de ZunZunEGUI, "Las cuentas de los colectores apostólicos", pp. 441-463; JaMme y Poncet, Offices et papauté; Le Roux, "Les percepteurs du pape", pp. 447-459; Farelo, "Payer au roi et au pape", pp. 55-106; Lunt, "Collectors of Clerical Subsidies", pp. 227-280, etc.

12 En teoría, García Fernández de Heredia fue nombrado titular de la mitra cesaraugustana en 1383. Sin embargo, por la situación de la ya mencionada indiferencia, no tomó posesión hasta 1387: PueYo Colomina, "Los vicarios generales del arzobispo", pp 745-746. García Fernández de Heredia fue también nombrado colector principal de la décima de 1393: Baucells, El fons "Cisma d'occident" de l'Arxiu Capitular, doc. 58; Morelló Baget, "La contribución de la Iglesia a las arcas del rey: a propósito de la recaudación”, p. 171. 13 Para profundizar en la idea de cómo los colectores principales de las décimas fueron mayoritariamente obispos de las principales ciudades de la Corona, véase las referencias citadas en la primera parte de
} 
Sea como sea, más allá del cargo de colector, la recaudación efectiva del impuesto caía en manos de una serie de subcolectores nombrados por el colector principal en cada uno de los obispados. A grandes rasgos, la labor que debían desempeñar estos agentes, con la colaboración de oficiales reales, consistía en recaudar las cantidades provenientes de los beneficios no exentos de pago, labor compleja y llena de dificultades, donde el propio clero puso muchas veces impedimentos. Como se ha puesto también de manifiesto en otras ocasiones, la labor de los subcolectores parece indicar que estos debían ser buenos conocedores del territorio en el que desarrollaban su función y que tenían cierta experiencia en la administración y gestión de las finanzas eclesiásticas o regias ${ }^{14}$. Por lo que aquí nos interesa, los subcolectores de la décima bienal recaudada entre 1387 y 1389 se nombraron en junio de 1387, cuatro meses antes de que comenzase la primera paga. En agosto de 1387 se nombraron aquellos que debían estar al frente de la décima de 1389 y, en octubre de 1390, quienes se debían encargar de percibir la décima de 1391 (véase cuadro 2).

\section{Cuadro 2.}

Subcolectores de las décimas concedidas en 1387

\begin{tabular}{llll}
\hline & Décima de 1387 & Décima 1389 & Décima 1391 \\
\hline Barcelona & $\begin{array}{l}\text { Nicolaú Morató, canónigo } \\
\text { de la catedral de Vic }\end{array}$ & - & $\begin{array}{l}\text { Pere Descoll, canónigo y } \\
\text { sacristán del monasterio } \\
\text { de Santa Maria de l'Estany } \\
\text { de Vic }\end{array}$ \\
\hline Elna & $\begin{array}{l}\text { Fray Antonio, abad del } \\
\text { monasterio de La Real de } \\
\text { Perpiñán }\end{array}$ & Idem & Idem \\
\hline Gerona & $\begin{array}{l}\text { Francesc Corona, pres- } \\
\text { bítero del monasterio de } \\
\text { San Daniel de Gerona }\end{array}$ & Idem & $\begin{array}{l}\text { Felip de Palau, rector del } \\
\text { hospital de la catedral de } \\
\text { Gerona }\end{array}$ \\
\hline Huesca & $\begin{array}{l}\text { Martín de Isábal, vicario de } \\
\text { la Iglesia de San Martin de }\end{array}$ & Idem \\
\hline Huesca & & \\
\hline
\end{tabular}

la obra de Tello Hernández, Pro defensione regni. Para una visión más general: Favier, Les finances pontificales, pp. 100 y ss.

14 FAVIER, Les finances pontificales, pp. 102-110, quien alaba la labor de estos subcolectores que pasaron -hasta cierto modo- desapercibidos para la administración pontificia, si bien su labor resultaba esencial para la recaudación del impuesto: Le Roux, "Des collecteurs specialisés”, pp. 107-129; Tello Hernández, Pro defensione regni; Bertran Roigé, "La dècima apostolica: l'exemple d'Elna (1391)", p. 457. Con todo, estos patrones de comportamiento, en cierto modo repetidos, nos permiten comprobar que la recaudación de la décima no debía resultar nada sencillo, De ahí que G. Mollat y C. Samaran, entre otros, señalaran la importancia de los obispos en relación con la percepción de las décimas (CAUSSE, Église, finance et royauté, pp. 271 y ss). 
El RETORNO A LA OBEDIENCIA DE JUAN I: LA REINSTAURACIÓN DE LAS DÉCIMAS PONTIFICIAS...

\begin{tabular}{|c|c|c|c|}
\hline & Décima de 1387 & Décima 1389 & Décima 1391 \\
\hline Lérida & $\begin{array}{l}\text { Francesc Borredà, abad del } \\
\text { monasterio de Santa Maria } \\
\text { d'Escarp }\end{array}$ & Idem & $\begin{array}{l}\text { Joan de Peralta, canónigo } \\
\text { de la catedral de Lérida }\end{array}$ \\
\hline Mallorca & $\begin{array}{l}\text { Bartomeu Manresa, } \\
\text { canónigo de la catedral de } \\
\text { Mallorca }\end{array}$ & Idem & Idem \\
\hline $\begin{array}{l}\text { Segorbe- } \\
\text { Albarracín }\end{array}$ & $\begin{array}{l}\text { Salvador de Gerp, arce- } \\
\text { diano de Santa María de } \\
\text { Albarracín }\end{array}$ & Idem & Idem \\
\hline Tarazona & Sacristán de Tarazona ${ }^{15}$ & - & - \\
\hline Tarragona & - & $\begin{array}{l}\text { Guillem Ferrer, canónigo } \\
\text { de la catedral de Tarragona }\end{array}$ & Idem \\
\hline Tortosa & $\begin{array}{l}\text { Andreu de Coscó, canónigo } \\
\text { de la catedral de Tortosa }\end{array}$ & Idem & Idem \\
\hline Urgel & $\begin{array}{l}\text { Francesc de Aguilar, } \\
\text { canónigo de la catedral } \\
\text { de Urgel }\end{array}$ & - & - \\
\hline Valencia & - & $\begin{array}{l}\text { Bartomeu del Castellar, } \\
\text { beneficiado de la catedral } \\
\text { de Valencia }\end{array}$ & Idem \\
\hline Vic & - & $\begin{array}{l}\text { Bernat Despujol, canónigo } \\
\text { de la catedral de Vic }\end{array}$ & Idem \\
\hline Zaragoza & $\begin{array}{l}\text { Joan Bovet, canónigo de la } \\
\text { catedral de Vic }\end{array}$ & - & $\begin{array}{l}\text { Joan Bovet, canónigo de la } \\
\text { catedral de Vic }\end{array}$ \\
\hline
\end{tabular}

Gracias a los libros de colecta y los albaranes testimoniales podemos saber quiénes fueron los subcolectores a lo largo de este periodo. Tal como puede verse en el cuadro, predominan los canónigos diocesanos (más del 50\% del total), seguidos de otros abades y religiosos del clero regular (se sitúan en torno al 23\%). La mayor parte de ellos repiten el cargo en dos o tres recaudaciones, por lo que formaban parte del sistema consolidado. De todos modos, un dato que nos debe hacer reflexionar es que, en algunos obispados, los subcolectores a la cabeza no formaban parte directamente de esa diócesis. Me explico, en el obispado de Zaragoza, parece ser que el subcolector

$\overline{15}$ Desconocemos el nombre de este subcolector. 
de las tres décimas fue un canónigo de Vic, Joan Bovet ${ }^{16}$. En Barcelona, en la décima de 1387, también ocupó el cargo de subcolector otro canónigo de la catedral de Vic, Nicolau Morató, y en 1391 lo hizo Pere Descoll, sacristán del monasterio de Santa Maria de l'Estany de Vic ${ }^{17}$. Obviamente, esto no parece casual ya que, recordemos, el colector principal, García Fernández de Heredia, había sido obispo de Vic en los años anteriores a los aquí estudiados. Además, por ejemplo, en el caso de Nicolau Morató, además de ser capellán real, lo documentamos como receptor general de parte del subsidio que se solicitó a los eclesiásticos catalanes para la celebración del jubileo del rey que estaba previsto para 1386, cuando se cumplían 50 años del acceso al trono del Ceremonioso ${ }^{18}$.

\subsection{Los ingresos de las décimas}

Gracias a las fuentes consultadas, podemos conocer la recaudación total en muchos de los obispados estudiados. Sin embargo, debemos tener en cuenta que no disponemos de datos completos para todos ellos, por lo que la suma total sería superior. Así, según la información disponible, la recaudación de la décima de 1387 ascendió, aproximadamente, a 19.194 1.b. (383.887 s.b.); la décima de 1389 a 10.146 1.b. (202.918 s.b.); y la de 1391 a 20.426 1.b. (408.515 s.b.). Sin embargo, estipulamos que la percepción total de cada recaudación no debió ser inferior a las 30.000 l.b. (600.000 s.b.), tal como se observa en las recaudaciones inmediatamente posteriores ${ }^{19}$.

Por arzobispados, la provincia de la tarraconense (formada por Tarragona, Barcelona, Gerona, Vic, Urgel, Tortosa, Lérida y Valencia) recaudó entre el 60-65\% del total. Por su parte, el arzobispado de Zaragoza (compuesto por Zaragoza, Huesca, Tarazona y Segorbe-Albarracín) contribuyó con un 20-25\%. Mallorca, hizo lo propio con un 5-10\% y Elna suponía en torno al $10 \%$ del total ${ }^{20}$. Por obispados, las diócesis catalanas son las que se sitúan al frente de las recaudaciones: a Gerona, con unas 2.700 1.b. (55.500 s.b.), le sigue Elna (2.279 1.b. aprox.) y los obispados de Tarragona y Zaragoza (que se situaban en torno a las 2.400 1.b. aprox.). Por su parte, el obispado de Segorbe-Albarracín,

16 ACA, RP, MR, reg. 653, ff. 258v-259v (01/12/1390). Bovet también fue subcolector de la décima de 1393: Morelló BAget, "La contribución de la Iglesia a las arcas del rey: a propósito de la recaudación", p. 187.

17 Véase respectivamente: ACA, RP, MR, reg. 655, ff. 10v-11v (19/04/1390) y reg. 656, ff. 37r-38v $(10 / 10 / 1393)$.

18 En este caso, Morató fue el encargado, junto con Pere Guillem d'Estanybos, de acudir a los centros eclesiásticos de Cataluña para recaudar las cantidades acordadas del subsidio por el jubileo: SÁnchez Martínez, "La última ofensiva", p. 1457 y, en especial, la nota 15.

19 Entre 1393 y 1409, J. Morelló calculó que la recaudación anual de cada décima en toda la Corona de Aragón ascendía entre las 15.334 y 17.864 l.b., suma también similar a lo observado en las décadas anteriores (Morelló BAGEt, "La contribución de la Iglesia a las arcas del rey: a propósito de la recaudación", p. 175).

20 Elna, pese a tributar con la Corona de Aragón y ser sede episcopal del Rosellón y La Cerdaña, pertenecía a la provincia eclesiástica de Narbona 
uno de los de menor tamaño y escasamente poblado, contribuía apenas con unas 170 1.b. (3.600 s.b.). En última instancia, tanto el monto total de la recaudación como lo aportado por cada obispado se sitúa en los porcentajes habituales manejados para el resto de décimas del periodo ${ }^{21}$.

\section{Cuadro 3.}

\section{Ingresos de las décimas promulgadas en 1387 (en sueldos barceloneses) ${ }^{22}$}

\begin{tabular}{lccc}
\hline & Décima de 1387 & Décima de 1389 & Décima de 1391 \\
\hline Barcelona & 49.758 & & 48.646 \\
\hline Elna & 44.507 & 47.113 & 45.096 \\
\hline Gerona & 58.540 & 54.547 & 53.446 \\
\hline Huesca & 23.057 & 24.467 & 22.742 \\
\hline Lérida & 32.303 & 30.694 & 34.466 \\
\hline Mallorca & 24.040 & & 24.359 \\
\hline Segorbe- Albarracín & 3.660 & & 3.586 \\
\hline Tarazona & & & 37.515 \\
\hline Tarragona & & & 44.864 \\
\hline Tortosa & 42.495 & & \\
\hline Urgel & 50.454 & & 43.873 \\
\hline Valencia & & & \\
\hline Vic & 19.194 & & 20.426 \\
\hline Zaragoza & 55.073 & & \\
\hline & & & \\
\hline Total aprox. & 383.887 & & \\
\hline Total aprox. (en l.b.) & & & \\
\hline
\end{tabular}

${ }^{21}$ Así, por ejemplo, durante la colecta de las décimas de 1393 y 1397, Barcelona o Girona se situaron a la cabeza de la recaudación (en torno a los 30.000 s.b. anuales), mientras que los obispados de SegorbeAlbarracín, Tarazona o Huesca eran los que menos ingresaron a las arcas reales (Morelló BAGET, "La contribución de la Iglesia a las arcas del rey: a propósito de la recaudación”, pp. 175-176). Si comparamos con una situación anterior, los datos tampoco son muy diferentes. Durante la décima trienal de 1375, los obispados de la Tarraconense recaudaron un 63\% del total, frente al 20\% del arzobispado de Zaragoza, un $9 \%$ de Mallorca y un $8 \%$ de Elna, y los obispos que más ingresaron fueron los de Zaragoza, Girona y Elna (Tello Hernández, "La contribución eclesiástica a las demandas reales", p 174).

22 Los datos han sido reducidos a moneda barcelonesa. Véanse los anexos finales donde se da una información más detalla de cada colecta y cada obispado. 
Estos datos también nos indican patrones de comportamiento en la recaudación de la décima, así como malestar y problemas surgidos durante el proceso. En primer lugar, podemos decir que la implicación directa del colector principal, el arzobispo de Zaragoza, hizo que la recaudación fuese, en cierto modo, más rápida ${ }^{23}$. Así, por ejemplo, García Fernández de Heredia jugó un papel activo y diligente en los casos de impago. En octubre de 1393 remitió una carta a los capítulos metropolitanos y catedralicios donde les advertía que no podía permitir que tantos beneficios se declarasen insolventes en el pago. Resultado de ello, el colector emitió una serie de letras ejecutorias contra varios beneficios, entre las que destaca una contra el abad de Santes Creus y otra contra la cartuja de la Scala Dei de Zaragoza, por negarse a satisfacer las cantidades con las que fueron tasados; suma que en el caso del cenobio zaragozano ascendía a los 1.200 s.b. ${ }^{24}$. En segundo lugar, también es habitual que se repitan una y otra vez noticias sobre cantidades que aún quedaban por recaudar cuando se presentaba el libro de cuentas y que, en muchos casos, aparecen recogidos en los libros de atrasos ${ }^{25}$. Por ejemplo, en la décima de 1387, en el obispado de Barcelona se alude a que aún quedaban por percibirse, al menos, 4.539 s. 8 d.b. ${ }^{26}$; lo mismo sucedía en el obispado de Gerona, con una suma que alcanzaba los 4.991 s. 6 d.b. ${ }^{27}$. Una cantidad más elevada son los 11.380 s.b. (569 1.b.) que no se percibieron en el obispado de Elna de la décima de $1389^{28}$. También en diócesis de menor tamaño observamos estos problemas. En la misma décima, en el obispado oscense quedaron sin recaudar 1.372 s.j. que debían ir a parar a las arcas regias $^{29}$. Finalmente, en la décima de 1391 aumentaron estas cantidades pendientes y se añadieron ahora algunos pagos de beneficios que solo debían contribuir a las arcas regias debido a que, por diferentes razones, estaban exentas de pago ante la Cámara Apostólica. Esto es lo que sucedió con el prior de Santa Ana de Barcelona, quien tan solo contribuyó con 578 s.b. a la parte regia ${ }^{30}$. De igual modo, el arcediano de Játiva

\footnotetext{
23 En las décimas anteriores no documentamos a priori una intervención tan directa del colector principal. De hecho, eran más bien los subcolectores los que empleaban medidas coercitivas cuando había algún problema. Sin embargo, esta es una cuestión que aún está por analizar ya que hay estudiosos que otorgan un papel más relevante al colector. Para ello, se basan en los problemas ocasionados a la hora de percibir la décima por parte de muchos subcolectores y en la intervención más directa del colector principal (Mollat y Samaran, La Fiscalité Pontificale en France au XIV siècle, pp. 84-87).

24 ACA, RP, MR, reg. 1352, f. 74r.

25 Para el periodo analizado, tan solo conservamos un volumen de recaudación de restas de la décima bienal de 1387 y que recoge información de los obispados de Elna, Huesca, Lérida, Tarragona, Tortosa, Valencia, Barcelona, Vic y Zaragoza (ACA, RP, MR, reg. 1945).

26 ACA, RP, MR, reg. 1842, f. 115r.

27 ACA, RP, MR, reg. 1844, f. 215r.

28 ACA, RP, MR, reg. 1858, f. 57v.

29 ACA, RP, MR, reg. 1845, f. 122r. En este caso, disponemos de información más explícita donde se dice que aún había varios lugares del obispado que debían ciertas cantidades de la décima, tal como tiene anotados el racional, en un libro que se conserva "en lo cofret vert de so offici" (ACA, RP, MR, notaments, vol. 792, f. 15v).

30 ACA, RP, MR, reg. 656, ff. 37r-38v.
} 
y el maestre de Calatrava, solo libraron al rey la parte proporcional, la cual ascendía, al menos, a 2.826 s.b. ${ }^{31}$.

\section{El destino del impuesto: las asignaciones a Violante de Bar}

Como decíamos en la introducción, el monto recaudado por el monarca debía servir para sofocar las revueltas de Cerdeña ${ }^{32}$. Recordemos que la isla era feudo de la Santa Sede y que, entre 1323 y 1326, se incorporó oficialmente a los dominios de la Corona con licencia del papado ${ }^{33}$. La situación de la isla era compleja y, a finales de la década de 1360, tan solo quedaban bajo influencia del rey aragonés Cagliari, Alguero y Sassari, además de algunos pequeños enclaves ${ }^{34}$. Para hacer frente a esta situación, en 1371 el Ceremonioso buscó financiación a lo largo y ancho del territorio para dotar una armada dirigida por el condotiero inglés Walter Benedict ${ }^{35}$. Tras esta gran expedición, tal como explica M. Lafuente, el conflicto entre la monarquía y el judicato de Arborea entró en una fase de estancamiento, aunque hubo una mayor movilización diplomática, sobre todo tras la muerte de Mariano IV en 1375 y durante la regencia de Leonor de Arborea (1383-1404). De hecho, si bien en 1385 se firmó un acuerdo donde Leonor, al frente del judicato de Arborea, reconocía la titularidad de la corona, las tensiones entre Juan I y Leonor de Arborea estallaron en 1387. La situación se fue tensando y, en 1391, Juan I retomó la idea de llevar a cabo una nueva expedición militar, campaña que no se puso en marcha hasta $1409^{36}$.

Este complejo panorama es una muestra más de que las arcas regias estaban exhaustas como resultado de las campañas anteriores en la isla, de las nuevas tensiones con

\footnotetext{
31 ACA, RP, MR, reg. 1854, f. 124r.

32 De hecho, en los albarantes testimoniales se establece esto como la causa principal de la concesión de las décimas: “...en alguna ajuda de les despeses faedores per lo dit senyor Rey per recobrament del regne de Sardenya e de Còrsega, lo qual té en feu per la santa Esglèsia de Roma. E encara per esguard dels grans e necessaris càrrechs a la dita Esglèsia ocorrents per rabó del Scisma qui en aquella era per obra del maligne spirit, imposá dècima sobre totes e sengles rendes e sdeveniments eclesiàstichs a les dites persones eclesiàstiques pertanyents dins los regnes e terras del dit senyor, per II anys" (BERTRAN Roigé, "La dècima apostolica: l'exemple d'Elna (1391)", doc. 2, cit. ACA, RP, MR, reg. 656, ff. 53r-54r).

33 Respecto al contexto de esta época: Hinojosa, Jaime II de Aragón y el esplendor de la Corona, pp. y pp. 245- 259. Sobre la contribución del principado a la empresa sarda en la década de 1320: SÁNCHEZ Martínez, "Las ciudades y villas de Cataluña en la financiación”, pp. 341-378; OrTi, "Les alienacions del patrimoni”, pp. 239-272. Como referencia más actual y de síntesis de las campañas emprendidas para sofocar las revueltas en Cerdeña, remito al estudio de LAfuente Gómez, "La fiscalidad extraordinaria en la financiación de las guerras", pp. 113-146.

34 IBIDEM, pp. 135-144.

35 Parece ser que, resultado de las negociaciones en Cortes y Parlamentos, el Ceremonioso pudo disponer, a modo de préstamo, de unos 205.000 fl. (Lafuente Gómez, "La Respuesta de las Cortes”, pp. 126-127). 36 De hecho, desde 1407 ya no parece haber recaudaciones de la décima para sofocar las revueltas de la isla. En particular, a partir de la segunda década del siglo XV (y hasta mediados de siglo) el subsidio pasó a ser la única vía de contribución extraordinaria del clero en la Corona de Aragón. Sea como sea, para la evolución política de este periodo, más allá de la bibliografía mencionada anteriormente, véanse: ARIENZO, “La lotta contro gli Arborea in Sardegna", pp. 329-382; Boscolo,”Problemi mediterranei”, pp. 81-82.
} 
Castilla, así como de los problemas de Juan I para reunir Cortes durante su reinado ${ }^{37}$. Dicho de otro modo, y como ya se ha puesto de manifiesto en numerosas ocasiones, las demandas continuas por parte de la monarquía, con la correspondiente presión fiscal, permiten constatar que los recursos financieros y materiales de los que disponía el rey eran insuficientes. Asimismo, los mecanismos recaudatorios de la décima eran lentos para una hacienda que necesitaba apresuradamente una solvencia económica. Por ello, de nuevo, los financieros privados demostraron ser capaces de movilizar grandes sumas de dinero a cuenta de la posterior recaudación de las rentas e impuestos regios ${ }^{38}$.

Por lo que se refiere a las décimas, durante las décadas anteriores, el monto de este impuesto iba a parar de forma directa o indirecta a los principales financieros del momento que habían prestado grandes sumas al monarca: Eimeric Dusai y Jaume de Gualbes, primero, y Pere Descaus y Andreu d'Olivella, después ${ }^{39}$. Pues bien, entre 1387 y 1393 la situación había cambiado de actores. Sin duda, durante la década de 1380 aparecieron nuevos financieros que se situaron en primera línea de la monarquía ${ }^{40}$. Pero es que, además, en este momento, la gran mayoría de la recaudación de las décimas se habían asignado a la reina Violante de Bar por varios prestamos que había hecho al rey y a un número determinado de mercaderes y banqueros que se habían dedicado a prestar importantes sumas "en ajuda de supportar les despeses que li convenia", ya fuese para los gastos o "sosteniment" de Cerdeña u otras cuestiones, tal como se establece en varias cartas emitidas el 10 de diciembre de $1389^{41}$.

\footnotetext{
37 De hecho, tan solo reunió unas Cortes Generales en Monzón en 1388-1389, donde contó con una fuerte oposición de los brazos para conseguir el apoyo que pretendía: Acta Curiarum Regni Aragonum. Cortes Generales de Monzón 1388-1389 (Tomo V), en especial, pp. XVI-XXIV.

38 Como referencia al juego financiero del momento, si bien no es objeto de este análisis, remito al artículo de Navarro Espinach, "Las elites financieras" (https://journals.openedition.org/e-spania/24259) у a la monografía de De la Torre, Grandes mercaderes de la Corona de Aragón.

39 Así, Eimeric Dusai y Jaume de Gualbes fueron los recibidores principales de la décima de 1371 (Morelló y Tello, "Los cambistas Dusai-Gualbes como gestores", pp. 189-223); Pere Descaus y Andreu d'Olivella de las décimas de 1375 y 1377 (Tello Hernández, "La contribución eclesiástica a las demandas reales", pp. 167-191); y Luchino Scarampi de parte de las décimas de finales del siglo XIV (Morelló BaGet, "La contribución de la Iglesia a las arcas del rey: a propósito de la recaudación”, pp. 179-184).

40 Como decíamos, estamos en el momento previo en el que los conocidos mercaderes Luchino Scarampi, de Asti, y Francesc Deudé, mercader de Sant Mateu, se convirtieran en los máximos prestamistas de la monarquía. Los monarcas vendieron a Scarampi un censal de 87.000 s.b. por el precio de 87.000 fl.; y a Deudé otro de $34.000 \mathrm{sb}$. por $34.000 \mathrm{fl}$. Los dos censales ascendían a 121.000 s.b. y se asignaron al pago de las pensiones anuales los ingresos procedentes de las rentas regias de Mallorca, así como de las primicias, causas pías, usuras y, como era de suponer, a la décima otorgada por el papa para la expedición a Cerdeña (SÁnchez Martínez, "El fisc de les usures en la Corona de Aragón", p. 200; Morelló Baget, "La contribución de la Iglesia a las arcas del rey: a propósito de la recaudación", p. 179 y ss). Véase asimismo en relación con las décimas de la década de 1390 y la devolución de los intereses por la deuda que contrajo la monarquía: MoRelló BAGET, "La contribución de la Iglesia a las arcas del rey: a propósito de la recaudación", pp. 179-184; FerRer y VeLA, "Un mercader italià a la Cort", pp. 301-478.

${ }_{41} \mathrm{~A} 1$ respecto, en varias ocasiones nos indican que se le asignaron a la reina los dos tercios de la décima por la moneda prestada al rey para Cerdeña "en paga e compensació de certa quantitat de moneda que la dita senyora li havia prestada per socorrer el regne de Sardegna e Corcega" (ACA, RP, MR, notaments, vol. 791, f. 27v y siguientes). Véanse como contexto sobre la situación de las rentas que la reina que tenía
} 
El recibidor general de la mayor parte de las cantidades de la décima fue Joan Muntrós, un antiguo conocido de la monarquía ${ }^{42}$. Este personaje había estado muy vinculado al rey y a la recaudación de las rentas pontificias durante el periodo de la indiferencia $\mathrm{y}$, de hecho, en 1387, fue también quien cerró el proceso de liquidación de la mencionada Cámara Apostólica Real ${ }^{43}$. Por lo que aquí nos interesa, podemos decir que Muntrós fue el encargado de librar las asignaciones a terceros en cada una de las décimas; porcentaje que, según la información disponible, ascendió -al menos- hasta el 70-75\% del monto total ${ }^{44}$. Para ello, recibía el dinero a través de los oficiales regios y los mismos subcolectores, así como -en un principio- a través de la taula de los cambiadores barceloneses Joan y Lluis de Gualbes. Y es que, gran parte de lo recaudado de la décima, pasaba antes o después por la banca privada de estos financieros que se encargaban de hacer la dita o el traspaso a Muntrós ${ }^{45}$.

Sea como sea, la mayor parte de la recaudación estaba destinada a un conjunto de mercaderes con los que la reina estaba en deuda. El listado lo formaban Berenguer de Cortilles (de Zaragoza), Arnau d'Alòs (de Barcelona), Pere Ferrer (de Solsona) y Martín de Antolín (de Tortosa). En particular, ya en agosto de 1387, la reina reconoció deber a estos mercaderes y sus procuradores $50.000 \mathrm{fl}$. por una venta de 36.180 robas de lana que habían hecho al mercader florentino Luchino Scarampi por mandato de la reina ${ }^{46}$. Centrándonos en los datos de la décima de 1389, Berenguer de Cortilles, Arnau d'Alòs, Pere Ferer y Martín de Antolín recibieron, al menos, 3.046 1.b. de los obispados de Elna, Lérida, Vic y Huesca, lo que suponía en torno a un $63 \%$ de total de la recaudación ${ }^{47}$.

asignadas por parte del monarca, los estudios de referencia de Ruiz Domingo, "Crédito, deuda y finanzas de la casa de la reina", pp. 353-376; Rodríguez Lajusticia, "Reinas y fiscalidad: Violante de Bar y la distribución de sus rentas", pp. 283-304.

42 "E munten les dates, pagues e messions que posats hever fetes de la dita part al senyor rey pertanyent, és a saber, a.n Johan de Muntrós de casa del dit senyor, ara com a reebedor general per lo dit senyor ordonat de la moneda de la dita dècima..." (Bertran Roigé, "La dècima apostolica: l'exemple d'Elna (1391)", doc. 2, cit. ACA, RP, MR, reg. 656, ff. 53r-54r).

43 Morelló Baget, "La gestió comptable de la Cambra Apostólica", pp. 337-341.

44 En particular, según los datos disponibles los porcentajes son los siguientes: el 83\% de la décima de 1387 , el $63 \%$ de la de 1389 , y el $76 \%$ de la de 1391 .

45 Así, por ejemplo, de la décima de 1389 en el obispado de Barcelona, 18.600 s.b. fueron a parar a esta banca privada para ser destinados a Muntrós (ACA, RP, MR, reg. 1842, f. 112r, f. 113v). En total, de los obispados de Elna, Barcelona y Girona, debieron depositarse en su taula, nada más y nada menos, 42.940 s.b. (2.147 1.b). ACA, RP, MR, reg. 1843 (Elna); reg. 1842 (Barcelona); y reg. 1844 (Girona).

46 La referencia de la tesorería aparece en: ACA, RP, TR, $514 \mathrm{ff}$. 15r-16v. La asignación de la décima a estos mercaderes se observa durante todo el periodo, pero más concreto a partir enero de 1390, cuando se asignó casi la totalidad de la décima de 1389 a tal fin: ACA, RP, MR, reg. 1849, f. 86v. Véase la información detallada en los albaranes testimoniales correspondientes: ACA, RP, MR, reg. 655, ff. 199r-200v. En la misma fuente, también se documenta que estos mercaderes recibieron durante los mismos años los ingresos del peaje de Calatayud (que también tenía asignados la reina) y que suponían unos ingresos anuales de 13.000 s.b.

47 ACA, RP, MR, reg. 1858 (Elna); reg. 1849 (Vic); reg. 1846 (Lérida); reg. 1845 (Huesca); reg. 1849 (Vic). No disponemos de más libros de cuentas, pero creemos que el patrón se repetiría en otros obispados. 
De la décima de 1391, la cantidad asignada directamente a los mercaderes fue en torno a 19.266 l.b., esto es, en torno a un $76 \%$ del total ${ }^{48}$.

$\mathrm{Al}$ analizar en profundidad los gastos de las décimas no solo podemos contemplar este trasvase a financieros. También nos da una visión muy amplia de la situación por la que pasaban las arcas regias y de las cantidades que eran debidas a otras instituciones, en especial y tal como hemos dicho, a la tesorería de Violante de Bar. Como es obvio, la implicación de la reina también fue importante. A través de una carta fechada en marzo de 1393, Violante solicitó al notario de Zaragoza, Pedro Sánchez del Postigo, que exigiese cobrar cualquier resta que quedaba por percibir de las décimas del arzobispado de Zaragoza y de los obispados de Huesca y Tarazona ${ }^{49}$.

Por acabar con este apartado, también hay otros personajes que recibieron sumas de la recaudación por diferentes motivos. En junio de 1391, el arzobispo de Zaragoza envió una carta a los subcolectores y demás comisarios de la décima para indicarles que le eran debidos, nada más y nada menos, 15.400 fl. (169.400 s.b.) a Francesca, mujer del tesorero Pere Desvall, por un préstamo que realizó al rey en 1387 por una deuda que alcanzaba la suma de $10.000 \mathrm{fl}$. y que aún no había sido satisfecha en su totalidad. De esta cantidad, fueron recaudados, al menos, 3.500 fl. (38.500 s.b.) en la paga de san Juan de los obispados de Vic, Lérida, Urgel y Gerona ${ }^{50}$.

Por último, en la misma décima de 1391 se documenta otro pago de, al menos, 275 1.b. (5.500 s.b.) en favor de Joan Eiximenis, canónigo de Lérida y procurador del cardenal de Vivers, al cual, según una carta de la reina Leonor de marzo de 1393 y por mandato pontificio se le debían abonar anualmente durante seis años $1.500 \mathrm{fl}$. de Cámara para resarcir una deuda adquirida en mayo de 1389. Todo ello lo ratificó el colector general, que era el arzobispo de Zaragoza, y le asignó para ello parte de la décima de Urgel ${ }^{51}$.

\footnotetext{
48 ACA, RP, MR, reg. 1857 (Elna); reg. 1853 (Urgel); reg. 1851 (Lérida); reg. 1850 (Barcelona); reg. 1354 (Valencia); reg. 1851 (Lérida); reg. 1855 (Vic). P. Bertran, para la décima de 1391 en el obispado de Elna, establece que la cantidad que fue a parar a estos mercaderes ascendió hasta un $73 \%$ del total que tenía asignado Violante de Bar: Bertran Roigé, "La dècima apostolica: l'exemple d'Elna (1391)", p. 463; IDEM, "La dècima de la diòcesi d'Urgell", pp. 257-346; IDEM, "La dècima del bisbat de Barcelona (1391-1392)", pp. 371-498.

49 En particular, esta anotación hace referencia a la cantidad de 1.371 s.j. que quedaba pendientes de la décima de Huesca (ACA, RP, MR, notaments, vol. 792, f. 15v). Lo mismo lo volvemos a observar en alguno de los obispados catalanes, como en Vic (ACA, RP, MR, reg. 1849).

50 Del monto total debido, $5.000 \mathrm{fl}$. se asignaron sobre las décimas y otros 5.000 fl. sobre las rentas reales de Mallorca. Las cantidades a pagar se fueron distribuyendo en cada semestre, por ejemplo, en el obispado de Barcelona: 2.000 s.b. en noviembre de 1391; 3.300 s.b. en noviembre de 1392 y 9.300 s.b. en julio de 1393 (ACA, RP, MR, reg. 1850, f. 144r).

51 ACA, RP, MR, reg. 1853, f. 180r.
} 


\section{Consideraciones finales: un nuevo ciclo en el impuesto de la décima}

A través del análisis de las tres colectas aquí estudiadas hemos podido completar, a grandes rasgos, el mapa de las décimas seriadas de la segunda mitad del siglo XIV ${ }^{52}$. Cada una de estas recaudaciones supuso unos ingresos relativamente previsibles y continuos a las arcas del rey y, si bien estas sumas debían servir para hacer frente a las revueltas de Cerdeña, la realidad fue diferente. Como hemos visto, la mayor parte de los ingresos que tenían como destino la hacienda real, fueron a parar a la reina Violante de Bar, a través de una asignación de Juan I. A su vez, la reina lo destinó a satisfacer varias deudas que tenía con mercaderes que le habían prestado importantes sumas de dinero $^{53}$. Esto nos hace afirmar -una vez más- que la recaudación de la décima se empleó repetidamente durante todo el siglo XIV como garantía de pago a financieros con los que la corte estaba en deuda. Sin entrar en muchos detalles al respecto, podemos decir que, aproximadamente, entre 1387 y 1393 se percibían anualmente en toda la Corona unas 15.000-17.000 1.b. (300.000-340.000 s.b.) $)^{54}$. En total, entre 1387 y 1393, se recaudaron en el conjunto del territorio unas 79.921 1.b. De esta cantidad, obispados como Gerona, Zaragoza, Barcelona, Urgel o Tarragona aportaron a las arcas regias entre 7.000 y 8.300 1.b.; por contra, la diócesis de Segorbe-Albarracín no llegó a las 600 1.b. durante los seis años y obispados como Tarazona se situaron en torno a las 3.000 1.b. (vid. Gráfico 1). Por último, por lo que respecta a la propia administración de la décima, podríamos profundizar en varios aspectos que superarían los objetivos de este trabajo. Sin embargo, hay uno en el que conviene centrarnos: el del ascenso social de los colectores y subcolectores. Hemos dedicado un apartado menor a estos agentes y, sin duda, es necesario un análisis profundo a nivel prosopográfico. Los colectores principales y los subcolectores tuvieron en la décima pontificia un instrumento de promoción social y jerárquica. Frecuentemente, muchos de ellos continuaron su ascendente carrera eclesiástica, a la vez que se enriquecieron consiguiendo mayores rentas. Este sería el caso del mencionado Nicolau Morató, que también fue consejero real y quien, tiempo después de actuar como subcolector, obtuvo algún que otro beneficio aparte del arcedianato de Liminyana y una canonjía en la Seo de Urgel ${ }^{55}$.

\footnotetext{
52 Tal como hemos dicho, el aparato administrativo de las décimas de mitad de siglo fue estudiado en su conjunto por M. Sánchez; las de la segunda mitad por E. Tello; y las de finales del siglo XIV y comienzos del siglo XV, por J. Morelló.

53 En este sentido, los gastos destinados a sofocar las revueltas de Cerdeña parecen quedar relegados a un segundo plano. Asimismo, los dispendios ordinarios, casi todo orientado a los salarios de subcolectores y escribas, eran menores. P. Bertran, para la décima de 1391, establece que tan solo un 6,4\% del total de la recaudación de la parte regia se destinó a este concepto (BERTRAN RoIGÉ, "La dècima apostolica: l'exemple d'Elna (1391)", p. 463).

54 Recordemos al respecto, que, tal como lo reconocía la reina, a los mercaderes Berenguer de Cortilles, Arnau d'Alòs, etc., se les había reconocido una deuda de, al menos, 50.000 fl. (550.000 s.b.) que se habían cargado en parte sobre este impuesto.

55 También sabemos que, al menos en 1406, dispuso de una canonjía en la rectoría de Sant Mateu de Tortosa, aunque parece ser que no podía estar al frente de todos estos beneficios sin una dispensa ponti-
} 
En definitiva, podemos decir que con estas tres décimas recaudadas entre 1387-1393 se instauró, de nuevo, el aparato administrativo pontificio que había quedado desmantelado durante los últimos años de vida de Pedro IV y que continuó, aproximadamente, hasta el Concilio de Constanza (1414-1418), cuando asistimos a un cambio en el régimen fiscal pontificio $^{56}$. Por lo que aquí nos interesa, las sumas percibidas se repartieron entre el rey y el papa, siguiendo la forma ya comentada. La importancia de este impuesto pontificio, y el interés que tenían ambas haciendas en tal exacción, quedó de manifiesto en cómo, desde 1393 y hasta poco antes de la muerte del rey Martin I, se recaudaron décimas en toda la Corona todos los años; eso sí, ya otorgadas por el papa aragonés Benedicto XIII (1394-1415). Tal como muestra J. Morelló para estos años, sus ingresos se emplearon en hacer frente a las deudas que tenía el rey con financieros y banqueros de la época; en particular, destaca el uso de las décimas de la década de 1390 para el pago de las pensiones anuales que se debían a los mercaderes Luchino Scarampi y Francesc Deudé por un censal de $121.000 \mathrm{fl}$. vendido por la monarquía.

ficia: Ferrer i MALlol, “Un aragonés consejero de Juan I y Martín el Humano”, p. 552 (cit. ACA, C, reg. 2182, f. 44r. 20/10/1406).

56 La muerte del rey Martín I, el cambio dinástico y el concilio de Constanza puso fin al régimen fiscal aviñonés y, por ende, a la concesión de décimas seriadas para estos fines: Morelló BAGET, "las relaciones monarquía-papado", pp. 233-263. 


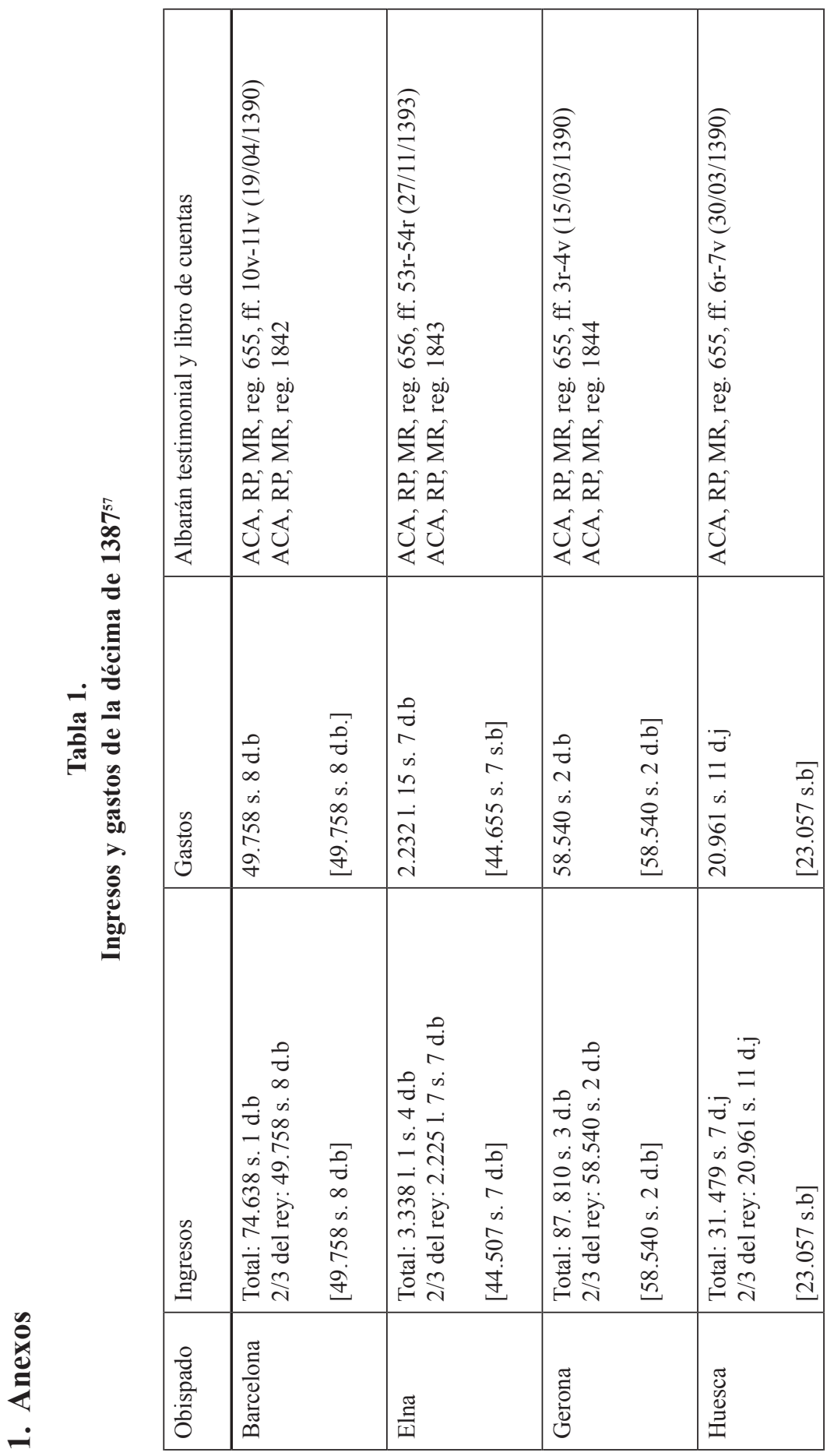

$\frac{\pi}{\pi} \pi$

ํㅗ

포

:옹

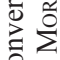

릴

迟

.

की

플 导

药

ㅎํㄹ

范

क

\& $\frac{1}{z}$

范 $\infty$

훙 옴

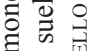

车西

음 엄

实

$\rightarrow$ 政

สี สำำ

它完

过 을

要

范

is.

을 융

웅

覃

으

की

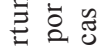

的范

ơ

की के

$\frac{0}{\pi} \cdot \frac{\pi}{0}$

in $\mathrm{a}$.

으

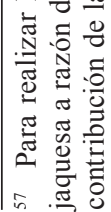




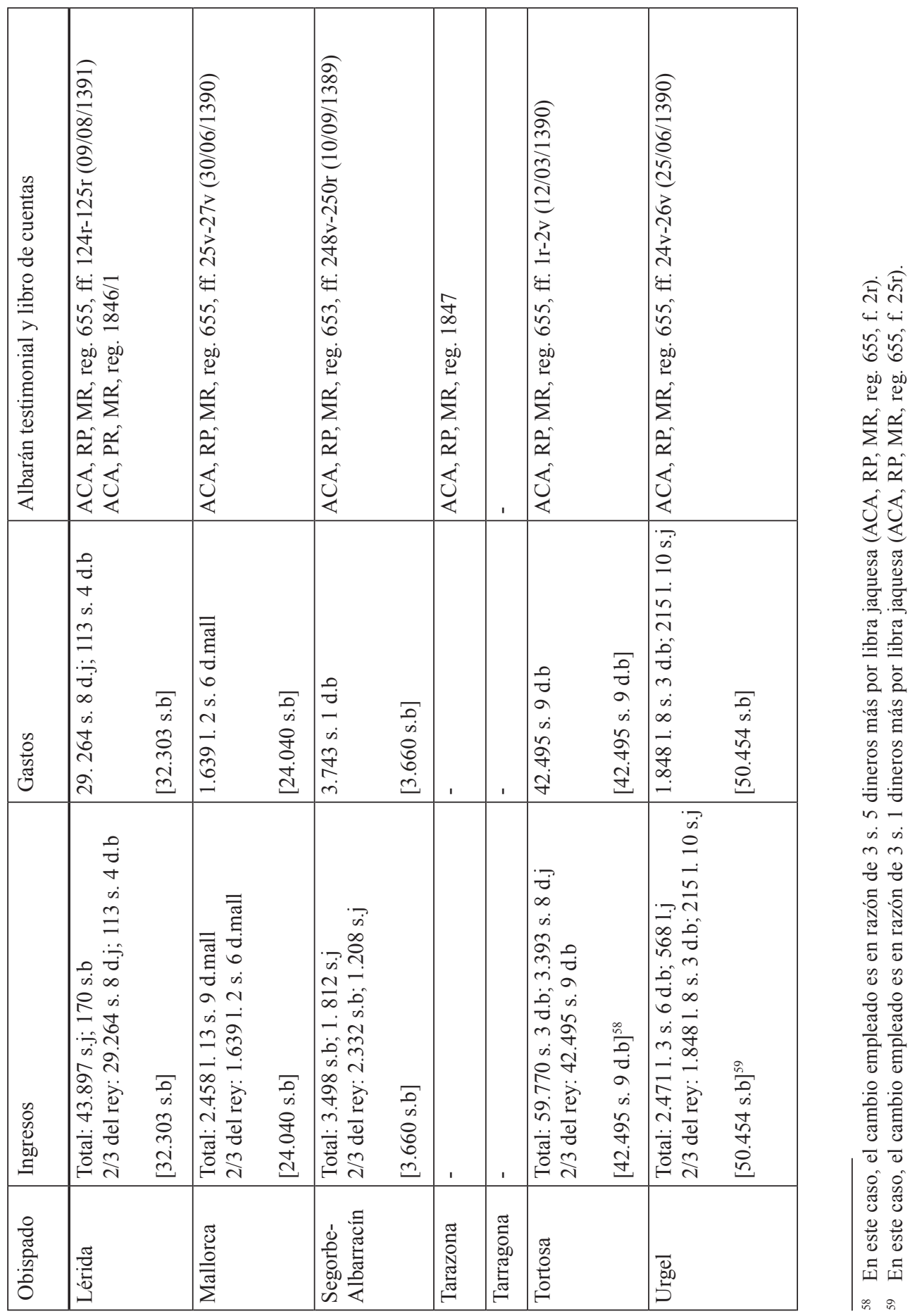



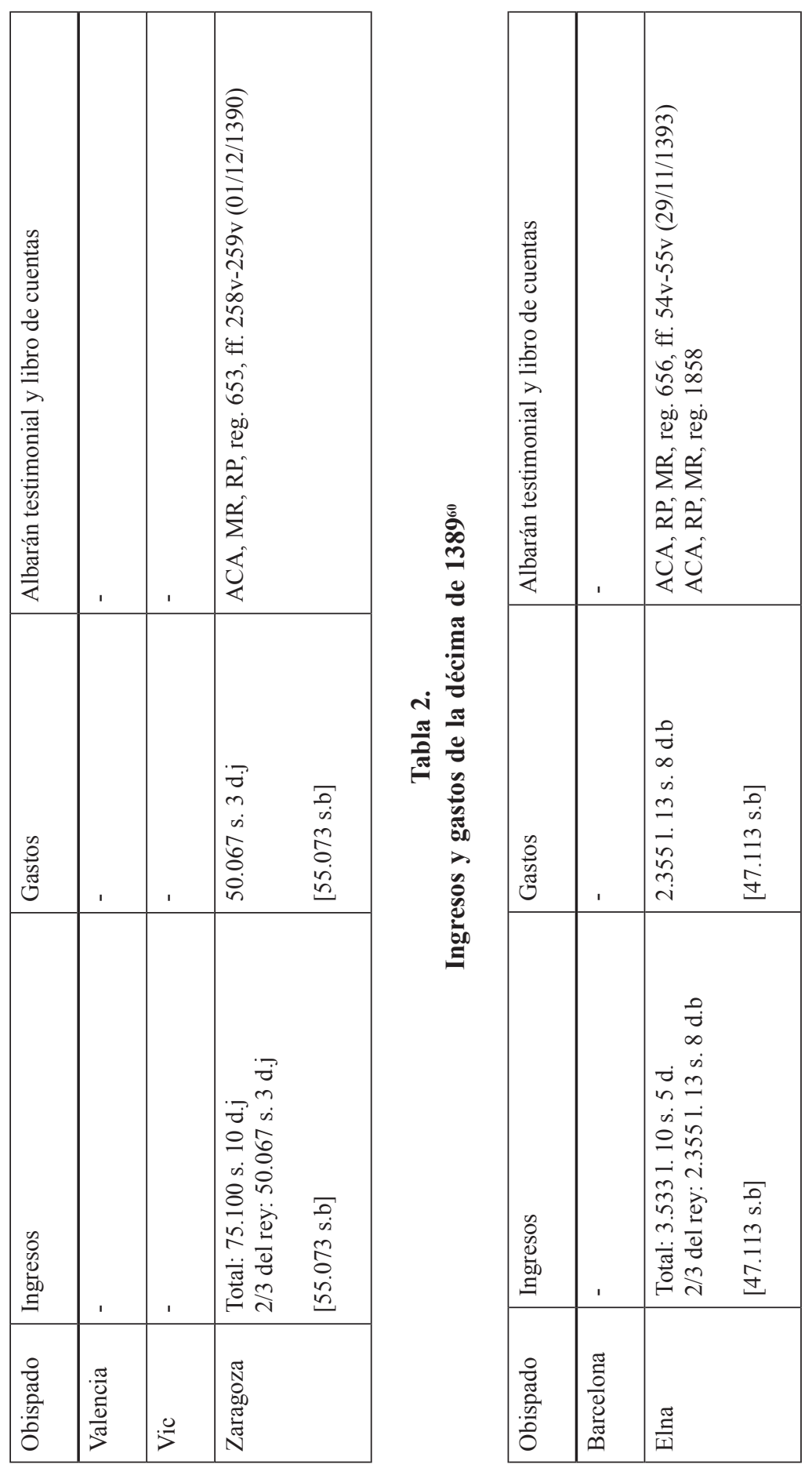

또 ㅇำ

봅

$\because \check{0}$

:올

$\sum^{2}$

0.0

还志

.

की

일

范

苟

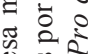

0 要

过

趈 $\infty$

옹 용

웜입

可

융

总

$\vec{\sigma}$

สี

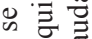

के 의

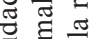

苟 $\frac{0}{8}$

is.응

뜬 응

过

घี

포

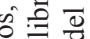

荕

年

के "ृ

8 क क

可

in

की

苞 용

ซ్

㐘

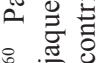




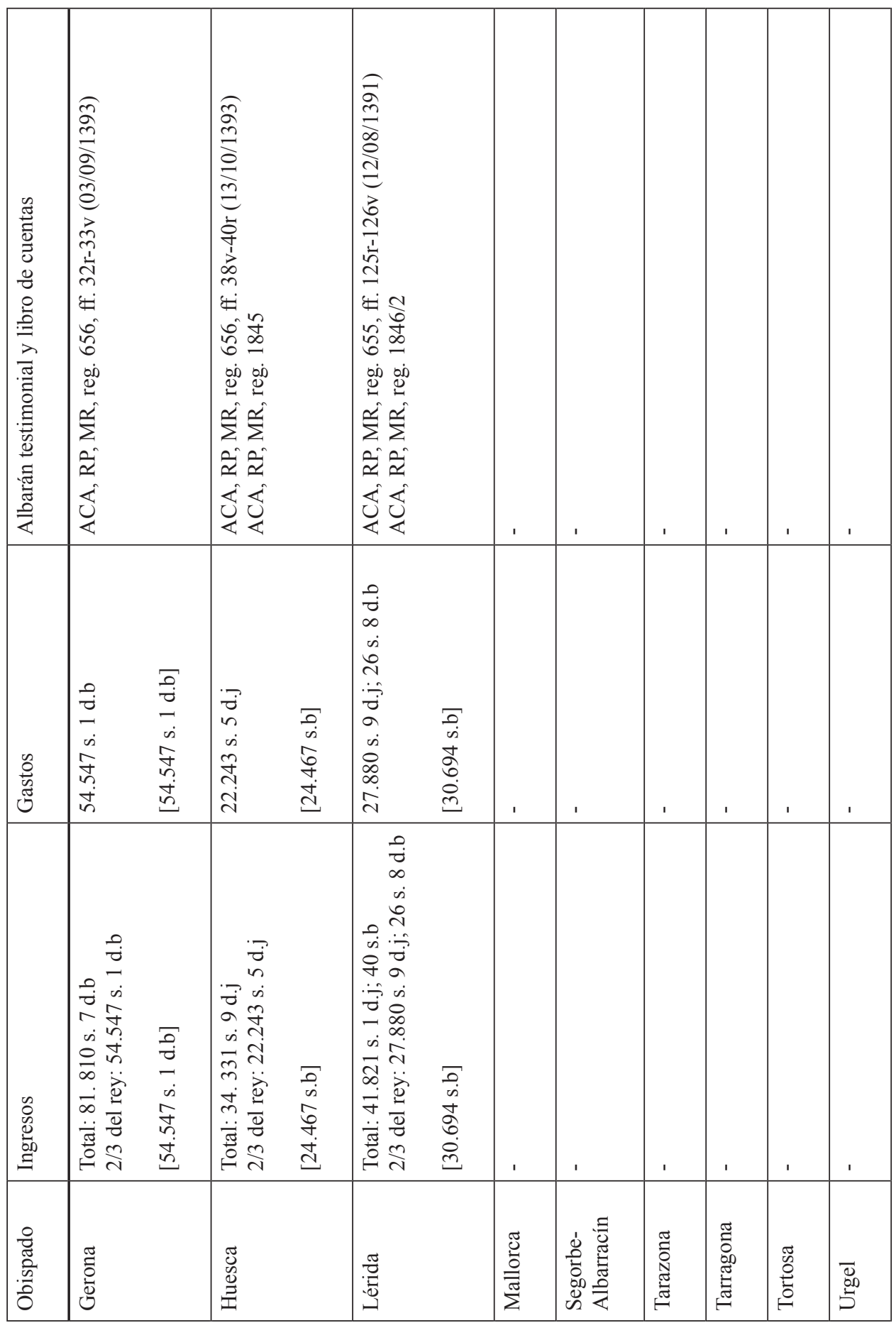



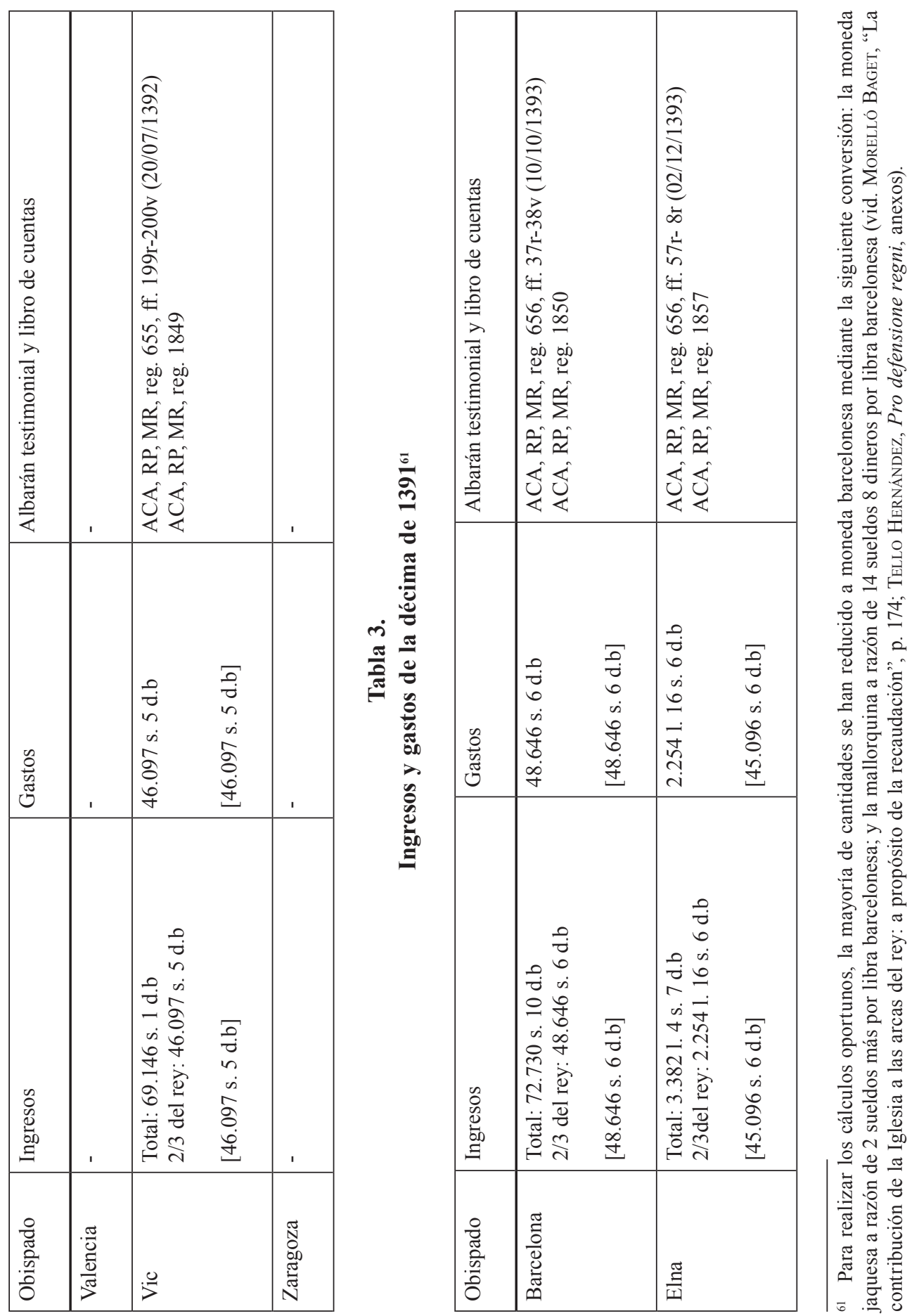

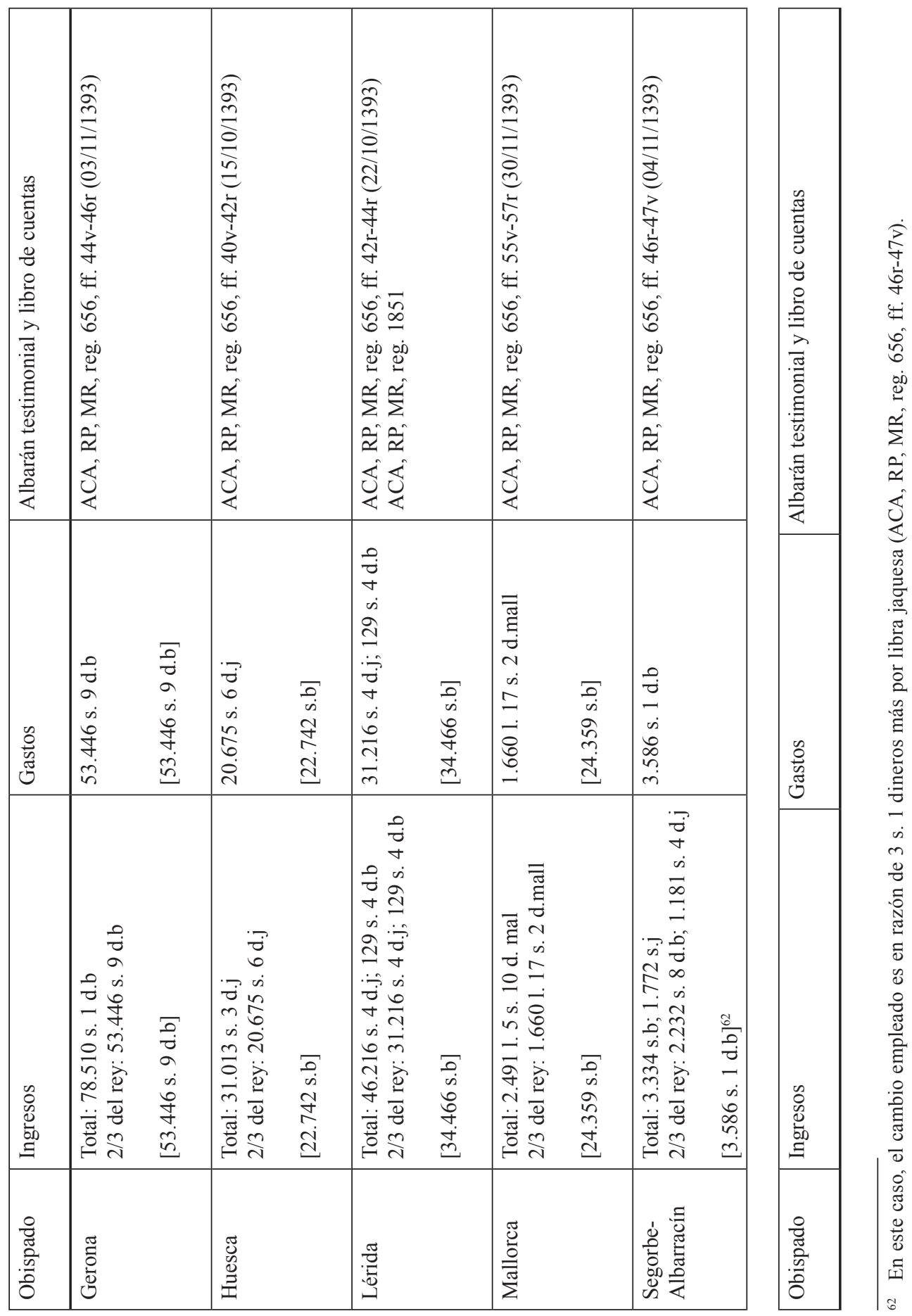


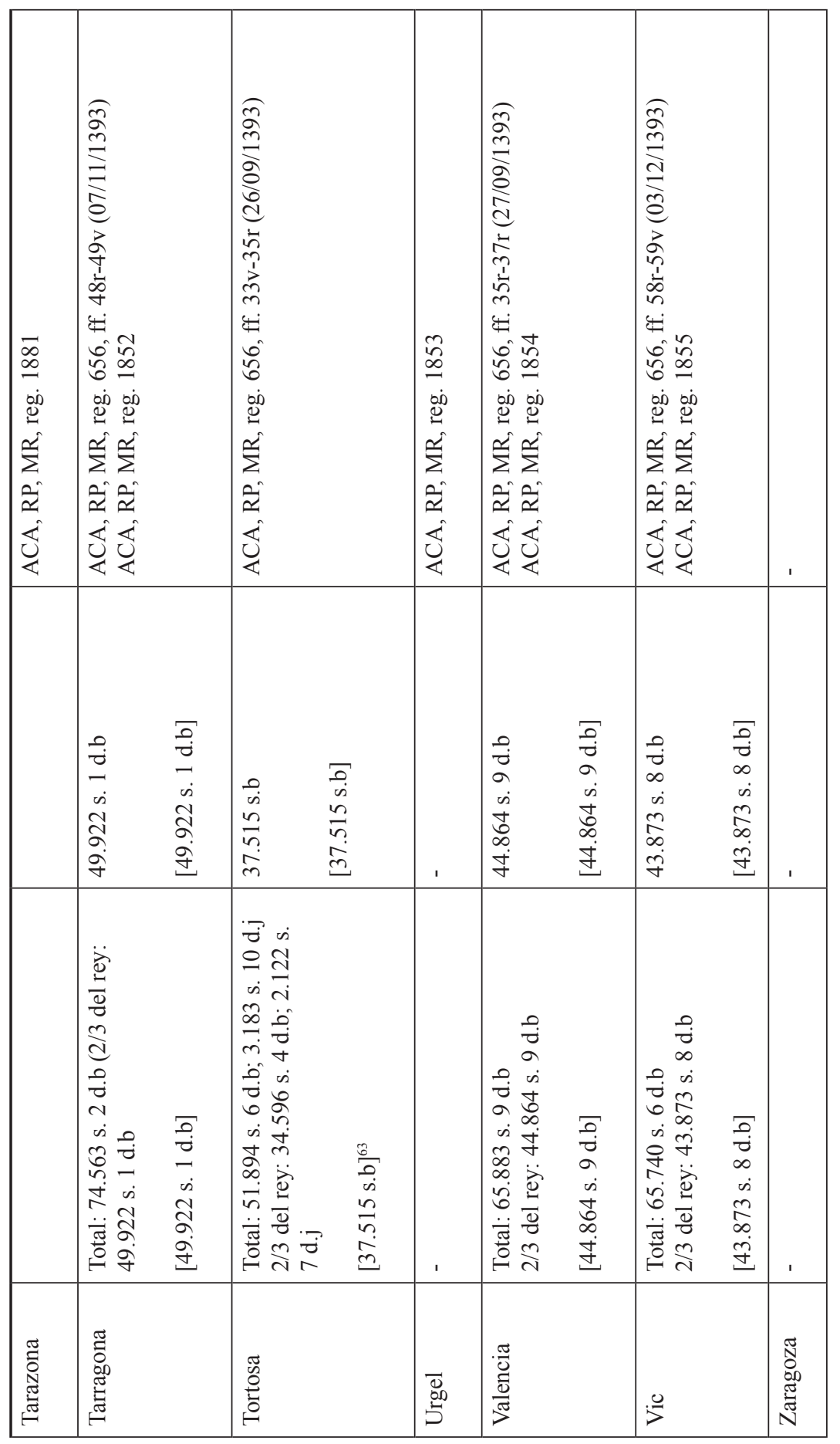

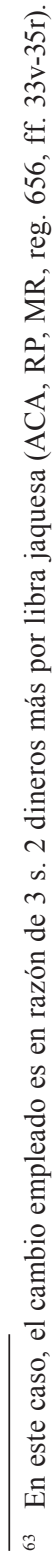




\section{Gráfico 1. \\ Ingresos totales del conjunto de décimas entre 1387 y 1393 \\ (en libras barcelonesas) ${ }^{64}$}

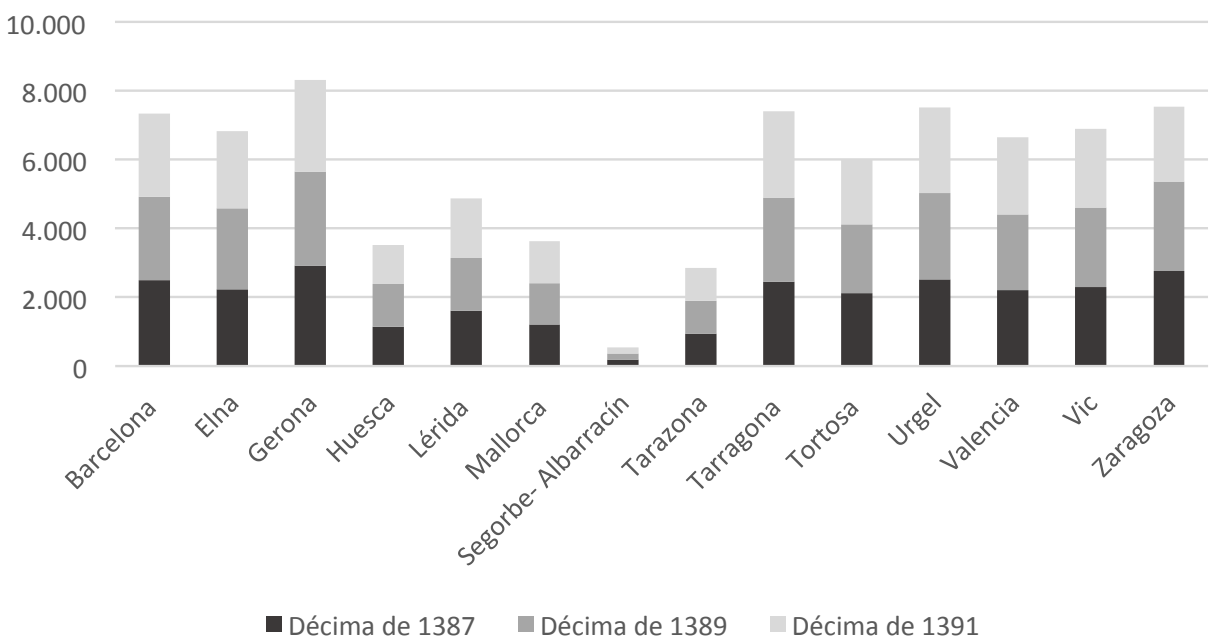

\section{Bibliografía}

ArIEnzo, Luisa de, "La lotta contro gli Arborea in Sardegna. La spedizione di Martino il Giovane, 1408-1409, e la fine del Giudicato", Martí l'Humà: el darrer rei de la dinastia de Barcelona, 1396-1410: l'Interregne i el compromís de Caspe, Maria Teresa Ferrer i Mallol (coord.), Institut d'Estudis Catalans, Barcelona, 2015, pp. 329-382.

Baucells i Reig, Josep, El fons “Cisma d'Occident” de l'Arxiu Capitular de la Catedral de Barcelona: Catàleg de còdexs i pergamins, Institut d'Estudis Catalans, Barcelona, 1985.

Bertran Roigé, Prim, "La fiscalitat eclesiástica en els bisbats catalans (1384-1392). Tipologies impositives y diferències territorials", Acta historica et archaeologica Mediaevalia, 18 (1997), pp. 281-300.

Bertran Roigé, Prim, "La dècima del bisbat de Barcelona (1391-1392)", Miscel-lània de Textos Medievals, 7 (1994), pp. 371-498.

Bertran Roigé, Prim, “La dècima apostolica: l'exemple d'Elna (1391)”, Estudios sobre renta, fiscalidad y finanzas en la Cataluña bajomedieval, Manuel Sánchez Martínez (coord.), Anejos del Anuario de Estudios Medievales-CSIC, Barcelona, 1993, pp. 455-486.

\footnotetext{
${ }^{64}$ Los datos de los que no tenemos referencia directa, se han extraido a través de extrapolaciones con respecto a las recaudaciones inmediatamente anteriores o posteriores.
} 
Bertran Roigé, Prim, "La dècima de la diòcesi d'Urgell corresponent a l'any 1391", Urgelia, 2 (1979), pp. 257-346

Boscolo, Alberto, "Problemi mediterranei dell'epoca di Pietro il Cerimonioso (13531387)", La Corona d'Aragó en el segle XIV. VIII Congreso de Historia de la Corona de Aragón, vol. 3, Caja de Ahorros y Monte de Piedad, València, 1973, pp. 65-99.

Causse, Bernard, Église, finance et royauté. La floraison des décimes dans la France du Moyen Age, 2 vols, Klincksieck, Paris-Llille, 1988.

De la Torre, Sandra, Grandes mercaderes de la Corona de Aragón en la Baja Edad Media: Zaragoza y sus mayores fortunas mercantiles 1380-1430, Anejos del Anuario de Estudios Medievales-CSIC, Barcelona, 2018.

FARELO, Mario, "Payer au roi et au pape. Les décimes pontificales imposées au clergé portugais pendant l'époque avignonnaise", Financiar el reino terrenal. La contribución de la Iglesia a finales de la Edad Media (siglos XIII-XVI), Jordi Morelló (ed.), Anejos del Anuario de Estudios Medievales-CSIC, Barcelona, 2013, pp. 55-106.

FAVIER, Jean, Les finances pontificales à l'époque du grand schisme d'Occident (13781409), École Française d'Athenes et de Rome, Paris, 1966.

Ferrer i Mallol, Maria Teresa, "Un aragonés consejero de Juan I y Martín el Humano", Aragón en la Edad Media, 14-15 (1999), pp. 531-562.

FERrer y Vela, Carles, "Un mercader italià a la Cort catalanoaragonesa: Luchino Scarampi”, Acta histórica et archaeologica Mediaevalia, 32 (2014), pp. 301-478.

Hinojosa, José, Jaime II y el esplendor de la Corona de Aragón, Nerea, Madrid, 2006. IvArs, Andrés, La “indiferencia” de Pedro IV de Aragón en el gran cisma de occidente, Asilo de huérfanos del S.C. de Jesús, Madrid, 1928.

JAMme, Armand, y Poncet, Olivier (eds.), Offices et papauté, XIVe-XVIIe siècle: charges, hommes, destins. Actes des tables rondes (Rome 2001- Rome 2002), École Française de Rome, Rome, 2005, pp. 761-782.

LAfuente Gómez, Mario, "La respuesta de las Cortes aragonesas a las demandas de la monarquía para combatir en Cerdeña (1367-1384)", Fisco, legitimidad y conflicto en los reinos hispánicos: (siglos XIII-XVII): homenaje a José Ángel Sesma Muñoz, Mario Lafuente, Carlos Laliena y Ángel Galán (eds.), Prensas Universitarias de Zaragoza, Zaragoza, 2019, pp. 115-140.

LAfuente Gómez, Mario, "La fiscalidad extraordinaria en la financiación de las guerras de Cerdeña por la Corona de Aragón (1320-1410)", Commercio, finanza e guerra nella Sardegna tardomedievale, Viella, Roma, 2017, pp. 113-146.

LE Roux, Amandine, "Des collecteurs specialisés aux collecteurs generalistes. L'établissement du système collectoral en Provence (1249-1514)", Financiar el reino terrenal. La contribución de la Iglesia a finales de la Edad Media (siglos XIII- XVI), Jordi Morelló (ed.), Anejos del Anuario de Estudios Medievales-CSIC, Barcelona, 2013, pp. 107- 129. 
Le Roux, Amandine, "Les percepteurs du pape: des agents efficacies", Structures et dynamiques religieuses dans les sociétés de l'Occident latin (1179-1449), Madeleine de Cevins y Jean-Michel Matz (eds.), Presses Universitaires de Rennes, Rennes, 2010, pp. 447-459.

LunT, William E., "Collectors of Clerical Subsidies granted to the king by the English clergy", The English Government at Work, 1327- 1336. Vol. II: Fiscal Administration, James F. Willard, William A. Morris et alii (eds.), Medieval Academy of America, Cambridge, 1947, pp. 227- 280.

Lunt, William E., Papal Revenues in the Middle Ages, Columbia University Press, New York, 1943 (reimp. 1965).

MAINÉ Burguete, Enrique, Ciudadanos honrados de Zaragoza: la oligarquía zaragozana en la Baja Edad Media (1370-1410), Grupo de Investigación CEMA, Zaragoza, 2006.

Mollat, Guillem, y Samaran, Christian, La Fiscalité Pontificale en France au XIV siècle (Avignon et Grand Schisme d'Occident), A. Fontemoing, Paris, 1905 (reimp. 1968).

Morelló, Jordi, y Tello, Esther, "Los cambistas Dusai-Gualbes como gestores de la décima de 1371: estudio del modus operandi y de la red clientelar en la corona de Aragón", El sistema financer al final de l'Edat Mitjana: Instruments $i$ Mètodes, Pere Orti y Pere Verdés (coords.), Publicacions de la Universitat de València, València, 2020, pp. 189-223.

Morelló Baget, Jordi, "En torno a la disyuntiva décima/subsidio en Castilla y la Corona de Aragón durante la Baja Edad Media”, Hispania, 77/225 (2017), pp. 643-671.

Morelló BAget, Jordi, "La gestió comptable de la Cambra Apostólica al bisbat de Barcelona devers el 1390 (en temps del collector Guillem de Boudreville)", A l'entorn de la Barcelona medieval. Estudis dedicats a la doctora Josefina Mutgé i Vives, Manuel Sánchez, Roser Salicrú et alii (eds.), Anejos del Anuario de Estudios Medievales-CSIC, Barcelona, 2013, pp. 333-352.

Morelló BAget, Jordi, "La contribución de la Iglesia a las arcas del rey: a propósito de la recaudación de las décimas en la Corona de Aragón a finales del siglo XIV y principios del XV", El dinero de Dios. Iglesia y fiscalidad en el Occidente Medieval (siglos XIII-XV), Denis Menjot y Manuel Sánchez (eds.), Instituto de Estudios Fiscales, Madrid, 2011, pp. 167-190.

Morelló BAget, Jordi, "Las relaciones monarquía-papado en la etapa final del Gran Cisma y la sucesión de dos modelos distintos de transferencia fiscal en la Corona de Aragón", La Corona de Aragón en el centro de su historia 1410-1412. El Interregno y el Compromiso de Caspe (Zaragoza y Alcañiz 24, 25 y 26 de noviembre de 2010), José Ángel Sesma (dir.), Gobierno de Aragón, Zaragoza, 2011, pp. 233-263.

Morelló Baget, Jordi, "La maquinaria fiscal del papado aviñonés en la Corona de Aragón: la colectoría de Berenguer Ribalta (1400-1402)", Anuario de Estudios Medievales, 39/I (2009), pp. 65-125. 
Navarro Espinach, Germán, "Las elites financieras de la monarquía aragonesa entre Juan I y Alfonso V (1387-1458)", e-Spania [En ligne], 20 (2015) (https://journals. openedition.org/e-spania/24259).

ORTI, Pere, "Les alienacions del patrimoni reial i el finançament de la conquesta de Sardenya de 1323-1324", La Corona Catalanoaragonesa $i$ el seu entorn mediterrani a la baixa Edat Mitjana, Anejos del Anuario de Estudios Medievales-CSIC, Barcelona, 2005, pp. 239-272.

Pueyo Colomina, Pilar, "Los vicarios generales del arzobispo de Zaragoza García Fernández de Heredia (1383-1411): su nombramiento", Sit liber gratus, quem servulus est operatus: studi in onore di Alessandro Pratesi, ed. Vaticana, Città del Vaticano, 2012, pp. 745-760.

Rodríguez Lajusticia, Francisco S., "Reinas y fiscalidad: Violante de Bar y la distribución de sus rentas entre 1389-1393", Reinas e infantas en los reinos medievales ibéricos: Contribuciones para su estudio, Miguel García-Fernández y Silvia Cernadas (coords.), Universidad Autónoma de Madrid-Instituto Universitario La Corte en Europa, Madrid, 2018, pp. 283-304.

Ruiz Domingo, Lledó, "Crédito, deuda y finanzas de la casa de la reina. Los capítulos entre la reina Violante de Bar y su nuevo tesorero, Berenguer de Cortilles", Historia. Instituciones. Documentos, 45 (2008), pp. 353-376.

SÁnchez Martínez, Manuel, "El fisc de les Usures en la Corona de Aragón a principios del siglo XV", Credito e usura fra teologia, diritto e amministrazione: linguaggi a confronto (secc. XII-XVI), Diego Quaglioni, Giacomo Todeschini et alii (coords.), École Française de Rome, Rome, 2005, pp. 197-228.

SÁnchez Martínez, Manuel, "Las ciudades y villas de Cataluña en la financiación de la conquista de Cerdeña (1321-1326)", Pagar al Rey en la Corona de Aragón durante el siglo XIV. Estudios sobre fiscalidad y finanzas reales y urbanas, Manuel Sánchez (ed.), Anejos del Anuario de Estudios Medievales-CSIC, Barcelona, 2003, pp. 341-378.

SÁnchez Martínez, Manuel, "La última ofensiva fiscal de Pedro el Ceremonioso: las demandas para el jubileo de 1386", Aragón en la Edad Media, 14-15 (1999), pp. 1.453-1.470.

SÁnchez Martínez, Manuel, "Fiscalidad pontificia y finanzas reales en Cataluña a mediados del siglo XIV: las décimas de 1349, 1351 y 1354", Estudis Castellonencs, 6 (1994-1995), pp. 1277-1296.

Sesma Muñoz, José Ángel (ed.), Acta Curiarum Regni Aragonum. T.V. Cortes Generales de Monzón 1388-1389, Grupo Cema, Zaragoza, 2009.

TAsis I MARCA, Rafael, "La indiferencia de Pere III en el Gran Cisma d'Occident", Jerónimo Zurita. La seva obra i l'estat general de la investigació histórica. VII Congreso de Historia de la Corona de Aragón, vol. 3, Barcelona, 1964, pp. 107-111. 
Tello Hernández, Esther, Pro defensione regni: Iglesia, monarquía y fiscalidad durante el reinado de Pedro IV (1349-1387), Serie Histórica de la EEHAR-CSIC, Madrid (en prensa. Plan editorial CSIC 2020).

Tello Hernández, Esther, «La comptabilité des décimes pontificales», Comptabilité (s). Revue d'histoire des comptabilités, 10 (2009) (http://journals.openedition.org/ comptabilites/2491).

Tello Hernández, Esther, "La Cámara Apostólica Real en la Corona de Aragón: aproximación a su estructura institucional y aparato financiero (1378-1387)", Identidades urbanas Corona de Aragón-Italia. Redes económicas, estructuras institucionales, funciones politicas (siglos XIV-XV), Germán Navarro, David Igual y Concha Villanueva (coords.), Prensas Universitarias de Zaragoza, Zaragoza, 2016, pp. 201-222.

Tello Hernández, Esther, "La contribución eclesiástica a las demandas reales en la Corona de Aragón: la décima de 1375", Hacer Historia desde el Medievalismo, Víctor Muñoz y Eduardo Aznar (eds.), Universidad de La Laguna, San Cristóbal de La Laguna, 2016, pp. 167-192.

VINCKE, Johanes, "Eine königliche camera apostolica", Römische Quartalschrift für christliche Altertumskunde und Kirchengeschichte, 41 (1933), pp. 306-310.

VINCKE, Johanes, "Iglesia en la Historia de la Corona de Aragón de los siglos XII, XII y XIV", Jerónimo Zurita. La seva obra i l'estat general de la investigació histórica. VII Congreso de Historia de la Corona de Aragón, vol. 1, Barcelona, 1964, pp. 267-285. ZunZunegui, José, "Las cuentas de los colectores apostólicos en Castilla durante el pontificado de Inocencio VI (arch. Vat. Collect. 114, ff. 32-49)", Anthologica Annua, 14 (1966), pp. 441-463. 